\title{
VILLOGLANDULAR PAPILLARY ADENOCARCINOMA OF THE UTERINE CERVIX- A RARE CASE REPORT
}

\author{
Radhika Yajaman Gurumurthy1, Nadig Siddharth Shankar², Mohan Raj C. S3, Nadig Sriram ${ }^{4}$
}

${ }_{1}^{1}$ Consultant Pathologist, Department of Pathology, Bhagavan Pathology Laboratory, Mysore, Karnataka, India. ${ }^{2}$ Consultant Pathologist, Department of Pathology, Bhagavan Pathology Laboratory, Mysore, Karnataka, India. ${ }^{3}$ Consultant Pathologist, Department of Pathology, Bhagavan Pathology Laboratory, Mysore, Karnataka, India. ${ }^{4}$ Consultant Pathologist, Department of Pathology, Bhagavan Pathology Laboratory, Mysore, Karnataka, India.

HOW TO CITE THIS ARTICLE: Gurumurthy RY, Shankar NS, Raj MCS, et al. Villoglandular papillary adenocarcinoma of the uterine cervix- a rare case report. J. Evolution Med. Dent. Sci. 2019;8(12):958-959, DOI: 10.14260/jemds/2019/213

\section{PRESENTATION OF CASE}

A 41-year-old lady came with the complaint of post-coital bleeding since five months. She had had two full term spontaneous vaginal deliveries and both children were alive and healthy.

Her general physical examination was unremarkable. On colposcopic examination, a suspicious polypoidal growth was noted in the endocervical region.

\section{CLINICAL DIAGNOSIS}

Cervical Carcinoma.

\section{PATHOLOGICAL DISCUSSION}

Patient initially underwent punch biopsy which was subsequently followed up by hysterectomy. Both biopsy specimen showed similar histomorphological features. A tumour was seen having villoglandular architecture. Occasional villi were branched and demonstrated a complex papillary pattern with glandular pattern. Each papilla showed central fibrovascular core lined by columnar epithelium showing mild to moderate atypia. No deep stromal or lymphovascular invasion was noted. The report was signed out as villoglandular papillary adenocarcinoma of the uterine cervix.

Villoglandular papillary adenocarcinoma (VGPA) is a rare variant of endocervical adenocarcinoma which was first described by Young and Scully in $1989 .{ }^{1}$ It accounts for 3.7$4.8 \%$ of cervical adenocarcinomas. ${ }^{2}$

The cytological features of VGPA on cervical smears are as follows: absence of neoplastic background; numerous abnormally stratified, papillary aggregations containing a large number of cells; a high N: C and small roundish nuclei; nuclear chromatin forming fine granules and some irregular, coarse granules; indistinct and occasionally small nucleoli. ${ }^{3}$

'Financial or Other Competing Interest': None.

Submission 30-01-2019, Peer Review 08-03-2019,

Acceptance 13-03-2019, Published 25-03-2019.

Corresponding Author:

Radhika Yajaman Gurumurthy,

\#1116, $5^{\text {th }}$ Cross, 1503, Srirampet,

Vinoba Road, Mysore-570001

Karnataka, India.

E-mail: radhikayg88@gmail.com

DOI: $10.14260 /$ jemds/2019/213

(c) $\underset{\mathrm{BY}}{\mathrm{NC}}(\mathrm{\textrm {NC }}$

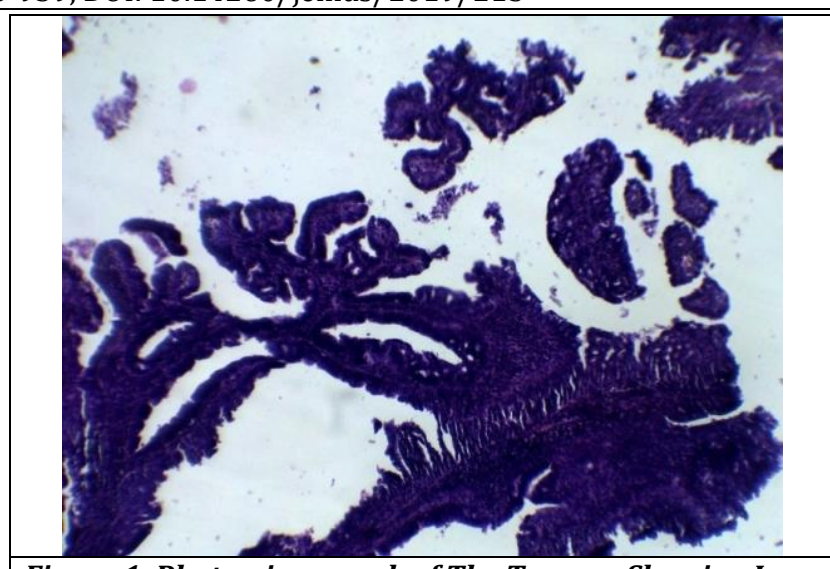

Figure 1. Photomicrograph of The Tumour Showing Long and Slender, Well Formed Papillary Structures. (H \& E, 10X)

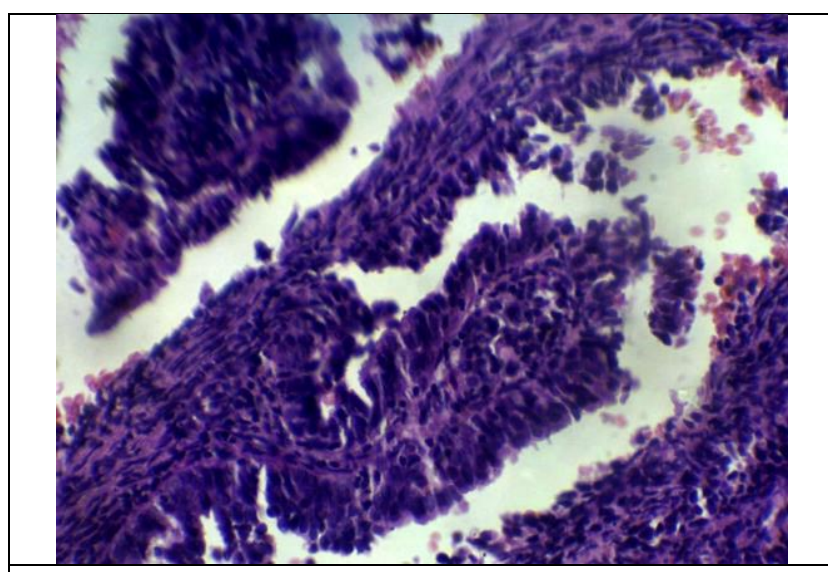

Figure 2. Higher Magnification Photomicrograph of The Papillary Structure Showing Central Fibrovascular Core Lined by Atypical Columnar Epithelium. (H \& E, 40X)

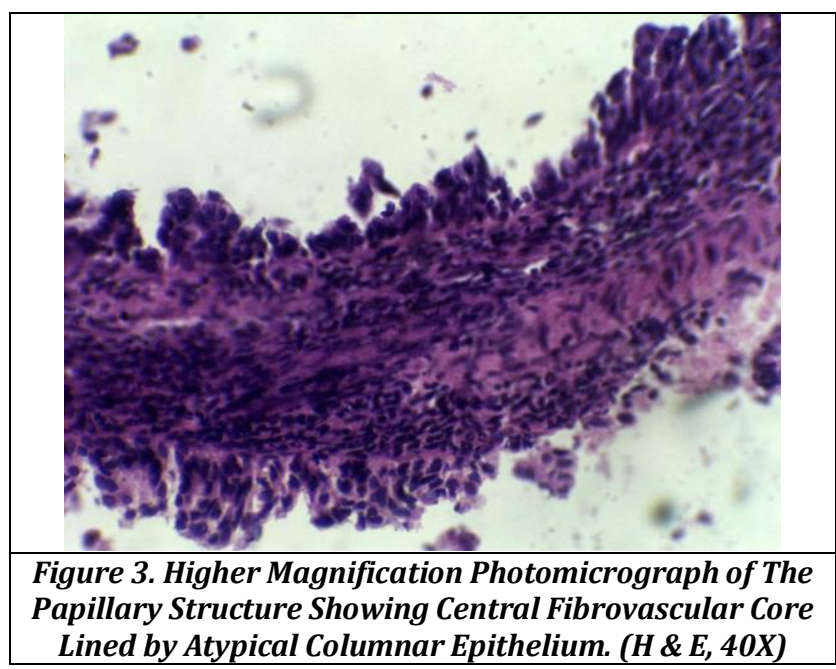


On gross examination, the tumours are mostly polypoidal or papillary neoplasms as seen in our case although occasionally they can present as infiltrative and friable lesions. ${ }^{4}$ The three important histopathological features of VGPA are: an exophytic growth pattern; papillary architecture and mild to moderate nuclear atypia, all of which were seen in present case. ${ }^{2}$ On microscopic examination, each papilla in the villoglandular structure, has a central pedicle that ranges in size and shape from short and thick to long and slender. 5 The central pedicle shows inflammatory cell infiltration. ${ }^{5}$ The villoglandular structures are lined by stratified glandular cells, showing mild to moderate atypia and mitotic figures. ${ }^{5}$ The epithelial lining can be of endometrial, endocervical or intestinal differentiation. ${ }^{2}$ Various authors have reported association of other patterns like squamous cell carcinoma, small cell carcinoma and adenocarcinoma in situ with VGPA. ${ }^{2}$ However, according to Young and Scully the term VGPA is reserved only for tumours with exclusive or almost exclusive villoglandular papillary pattern. ${ }^{2}$ Entire tumour must be examined before making diagnosis of VGPA. 6 Thus pre-treatment punch biopsy diagnosis has a lower diagnostic accuracy when compared with the final histopathology report. ${ }^{5}$

\section{DIFFERENTIAL DIAGNOSIS}

- Serous Papillary Adenocarcinoma

- Clear Cell Papillary Adenocarcinoma

- Endocervical Adenocarcinoma with A Minor Villoglandular Component

- Adenosarcoma

- Adenoma Malignum

\section{DISCUSSION OF MANAGEMENT}

VGPA is a rare tumour which is known to have a favourable course, infrequent lymphovascular space invasion/lymph node metastasis and better prognosis. ${ }^{7}$ Reports on the prognosis of VGPA are conflicting in various case reports, with most of them quoting excellent prognosis and few reporting rapid deterioration. ${ }^{8}$ Lymphovascular invasion, high mitotic count, deep stromal invasion, presence of high grade areas and coexistence of a different tumour are considered to be poor prognostic factors for VGPA. ${ }^{6}$

Treatment modalities range from cone biopsies to simple/radical hysterectomy with or without pelvic lymph node dissection and pre/post-operative chemoradiotherapy. ${ }^{1}$ But as the tumour is reported to have a favourable prognosis, depending upon disease stage, fertility requirements and follow-up conditions, a fertility sparing treatment could be considered first during the management. ${ }^{9}$ However, since most of the studies reporting the cases of VGPA are small and mostly retrospective with a short-follow up time, more prospective randomized controlled trials are required to confirm the prognostic significance of this rare entity.

\section{FINAL DIAGNOSIS}

Villo-Glandular Papillary Adenocarcinoma-Uterine Cervix

\section{REFERENCES}

[1] Salek G, Lalya I, Rahali DM, et al. Villoglandular papillary adenocarcinoma: case report. Pan African Medical Journal 2016;25:232.

[2] Tan GC, Shiran MS, Swaminathan M, et al. Villoglandular papillary adenocarcinoma of the uterine cervix with lymph node metastasis - a case report and review of literature. Med \& Health 2006;1(1):85-90.

[3] Nagai N, Hirata E, Kusuda T, et al. Villoglandular papillary adenocarcinoma of the uterine cervix responding to neoadjuvant chemotherapy with docetaxel and cisplatin: a case report. Int J Gynecol Cancer 2005;15(6):1187-90.

[4] Zhou QY, Chen HY, Yang SM, et al. Villoglandular papillary adenocarcinoma of the uterine cervix: a report of 4 cases and a review of literature. Oncology letters 2016;11(1):837-41.

[5] Zhao L, Xu T, Cui M, et al. A retrospective review of 11 cases of villoglandular papillary adenocarcinoma of the uterine cervix and a review of the literature. Oncology letters 2016;11(3):2164-8.

[6] Lataifeh I. Villoglandular papillary adenocarcinoma of the cervix. Annals of Medical Case Reports 2017;1:1-2.

[7] Wei CY, Qu YQ, He YY, et al. A retrospective review of 10 cases of villoglandular papillary adenocarcinoma of the uterine cervix including one with successful pregnancy. Reprod Dev Med 2018;2(2):120-7.

[8] Gurumurthy M, Lahiri R, Kennedy AM, et al. A case of villoglandular papillary adenocarcinoma of the cervix with vaginal skip metastasis. Gynaecologic Oncology Case Reports 2011;1(1):1-3.

[9] Young RH, Scully RE. Villoglandular papillary adenocarcinoma of the uterine cervix - a clinicpathologic analysis of 13 cases. Cancer 1989;63(9):1773-9. 